
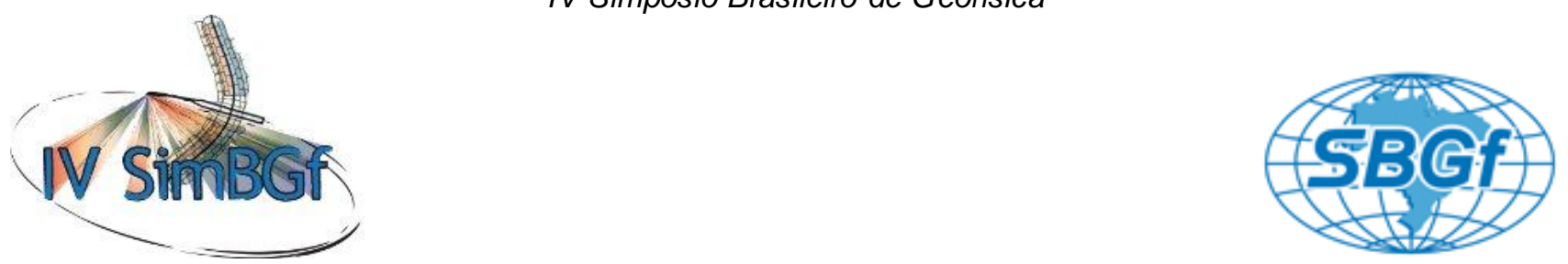

\title{
Estudos geofísicos ao longo do futuro trecho norte do metrô de Brasília: Resultados Preliminares
}

Eduardo Xavier Seimetz (edu.seimetz@gmail.com - Mestrando do Programa de Geociências Aplicadas - IG/UnB)

Marcelo Peres Rocha (marcelorocha@unb.br - Docente do Instituto de Geociências/UnB)

Welitom Rodrigues Borges (welitom@unb.br - Docente do Instituto de Geociências/UnB)

Luciano Soares da Cunha (lucianosc@unb.br - Docente do Instituto de Geociências/UnB)

Pedro Vencovski Nogueira (pvencovsky@gmail.com - Discente de Geologia do IG/UnB)

Marcio Maciel Cavalcante (thegemas@gmail.com - Técnico do Laboratório de Geofísica Aplicada - IG/UnB)

Paulo Araújo de Azevedo (paulopaico@hotmail.com - Discente de Física da Universidade Católica de Brasília)

\section{Copyright 2010, SBGf - Sociedade Brasileira de Geofísica}

Este tex to foi preparado para a apresentação no IV Simpósio Brasileiro de Geofísica, Brasília, 14 a 17 de novembro de 2010. Seu conteúdo foi revisado pelo Comitê Técnico do IV SimBGf, mas não necess ariamente representa a opi nião da SBGf ou de seus associados. E proibida a reprodução total ou parcial deste material para propósitos comerciais sem pr évia autorização da SBGf.

\section{Resumo}

Este trabalho apresenta resultados preliminares dos métodos geofísicos de sísmica de refração e de eletrorresistividade, próximo da via Norte do Eixo Rodoviário de Brasília, onde será realizada a construção do futuro trecho norte do metrô. O objetivo deste trabalho é definir um modelo geotécnico que possibilitará identificar a estrutura geológica e áreas de maior fragilidade estrutural. Estes resultados ajudarão a definir qual o melhor método a ser utilizado para orientar a construção do túnel por onde passará o metro.

\section{Introdução}

O uso de métodos geofísicos em problemas de engenharia vem crescendo nas últimas décadas, visto que estes geram informações que permitem diminuir custos e tempo de execução de obras. A principal vantagem de se utilizar métodos geofísicos é o fato de estes fornecerem informações da estrutura em subsuperfície de forma indireta, sem a necessidade de sondagens geológicas. No caso de obras como as de um metrô, o custo financeiro das sondagens geotécnicas representa uma parte significativa do orçamento da obra, além destes serem estudos pontuais, que não refletem totalmente a estrutura geológico/geotécnica da área. As investigações geofísicas não substituem as sondagens geotécnicas, no entanto, diminuem a sua quantidade e orientam a locação das mesmas.

A via do metrô brasiliense percorre um trajeto desde a rodoviária do Plano Piloto, passando por toda Asa Sul, até as cidades de Ceilândia e Samambaia (Figura 1). A partir de 2008, a Companhia do Metropolitano do Distrito Federal - METRÔ/DF passou a trabalhar na complementação da linha prioritária, sendo iniciados os estudos técnicos para a construção do trecho da Asa Norte e a expansão das vias em Samambaia e Ceilândia. A via da Asa Norte irá facilitar o deslocamento dos cidadãos do DF, principalmente no acesso ao campus da Universidade de Brasília - UnB.

Neste projeto foram utilizados os métodos geofísicos de sísmica de refração e de eletrorresistividade para estudar a estrutura do subsolo ao longo do futuro trecho norte do metrô de Brasília (Figura 2), com o objetivo de elaborar um modelo geotécnico que possibilitará identificar áreas de maior fragilidade estrutural, fornecendo informações que ajudarão durante as etapas de planejamento e execução da obra.

Uma descrição detalhada da geologia do Distrito Federal, em especial da Asa Sul, pode ser obtida nos trabalhos de OLIVEIRA (1996) e BLANCO (1995). Os resultados de um trabalho de caracterização geotécnica do subsolo do Plano Piloto de Brasília, utilizando dados de sondagens do tipo SPT (Standard Penetration Tests) (ALVES, 2009), foram utilizados durante a interpretação de nossos resultados para a Asa Norte.

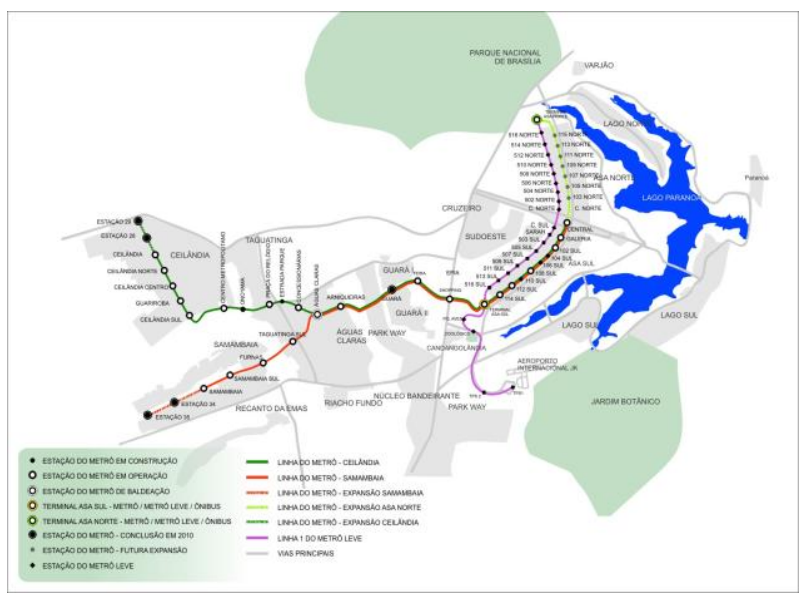

Figura 1: Mapa completo do futuro Metrô do Distrito Federal. (METRO-DF, 2010).

\section{Metodologia/ Problema Investigado}

Sísmica de Refração: O método de sísmica de refração baseia-se na propagação de ondas mecânicas geradas por fontes artificiais (marreta, rifle, entre outras), as quais são 
detectadas por receptores (geofones) fixados no solo, separados por uma distância constante entre eles. Com este método é possível determinar a velocidade das ondas que se propagam diretamente da fonte até o receptor, e também a das ondas refratadas criticamente nas interfaces limitantes entre cada tipo de material em subsuperfície, sendo então possível determinar a profundidade de cada interface.

Um dos problemas para a aplicação do método sísmico em áreas urbanas é o ruído causado principalmente pelo trafego de veículos. Estes ruídos prejudicam o sinal sísmico, mascarando o sinal de interesse. Para minimizar este problema, os levantamentos sísmicos foram realizados aos domingos e feriados aproveitando o fato do Eixo Rodoviário ser fechado pela administração distrital durante estes dias.

Um perfil de 115 metros foi feito próximo às quadras 108/109 da Asa Norte, paralelamente ao eixo rodoviário (Figura 02). Para aquisição dos dados sísmicos foi utilizado um sismógrafo da marca Geometrics do modelo Geode com 24 canais. Foram utilizados geofones de 40 $\mathrm{Hz}$. O espaçamento entre receptores foi de cinco metros. O primeiro receptor foi colocado na posição zero e os pontos de tiro foram efetuados nas posições de $-30,-5$, 57.5, 120 e 145 metros. A fonte de onda utilizada foi a marreta em placa de aço e, para cada tiro, foram executadas 25 marretadas, com o objetivo de aumentar a razão sinal/ruído. Os dados foram processados com o programa SEISIMAGER2D.

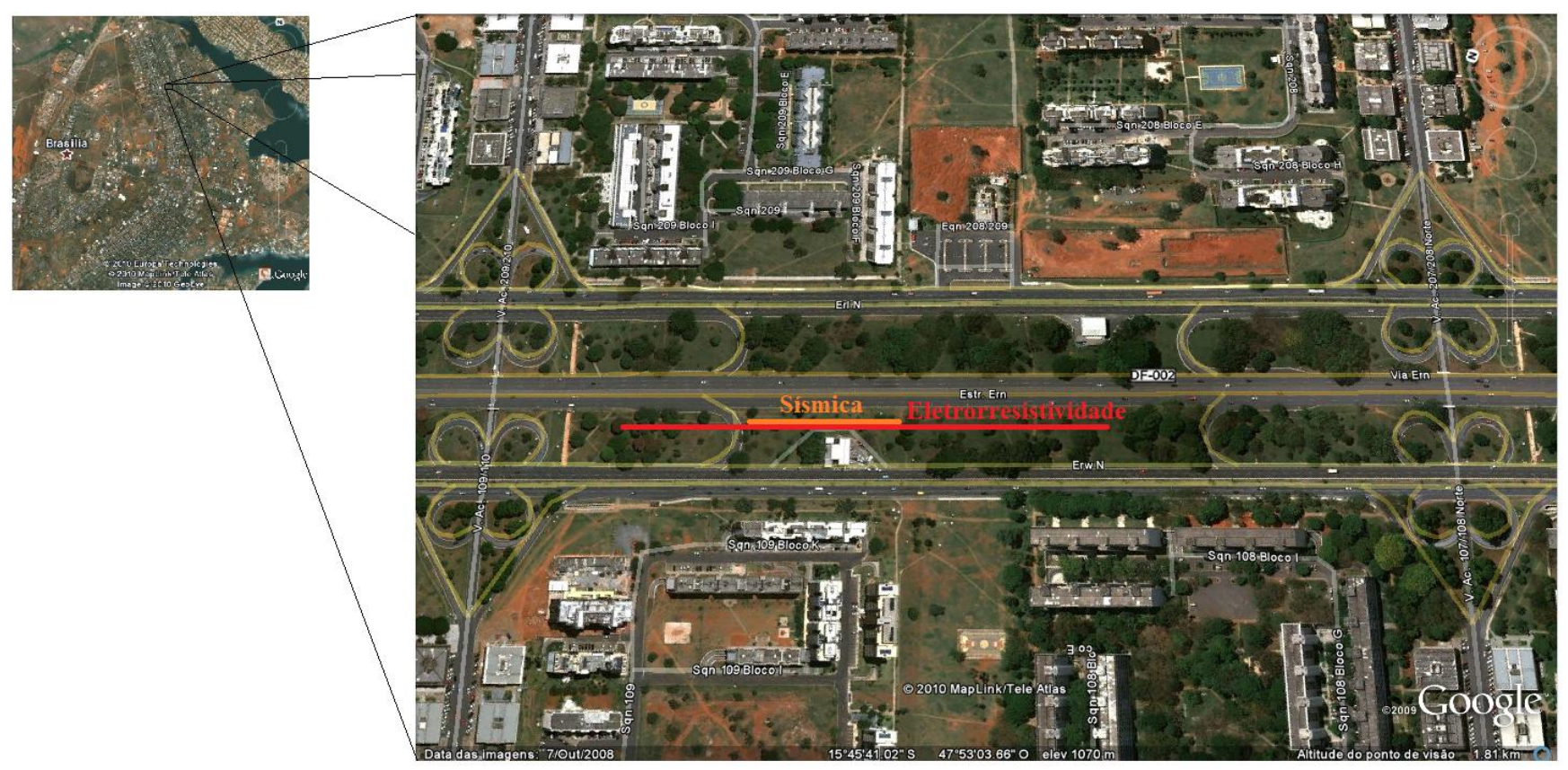

Figura 2: Área de estudo para levantamentos de sísmica de refração e eletrorresistividade (Quadras108 e 109 norte). Google Earth (2010).

\section{Eletrorresistividade:}

Este método baseia-se no fato de que o meio apresenta uma resistência à passagem de corrente elétrica. Nomalmente são utilizados quatro eletrodos (2 de corrente - $A B$ e 2 de potencial - MN) para a realização das medidas de fluxo de corrente e do potencial elétrico gerado pela mesma. Conhecendo-se a posição dos eletrodos em superfície e obtendo-se as leituras de corrente e de potencial é possível medir a resistividade elétrica do meio.

$\mathrm{Na}$ aquisição dos dados de eletrorresistividade foi utilizado um equipamento multieletródico da marca Iris, modelo Syscal, com 72 canais; sendo utilizados apenas 60 eletrodos. Os eletrodos foram espalhados a cada 5 metros. O arranjo adotado para realizar este levantamento foi o Dipolo-Dipolo com roll-on de 120 metros, ficando o arranjo com um comprimento total de 415 metros (Figura 2). O arranjo Dipolo-Dipolo foi escolhido por apresentar melhor sensibilidade à profundidade. Os dados foram processados com 0 programa RES2DINV.

\section{Resultados}

\section{Sísmica de Refracão:}

Mesmo realizando os levantamentos aos domingos (quando o eixo rodoviário está fechado), o nível de ruído ainda permaneceu alto. Isso se deu principalmente devido ao movimento de carros nos eixos $L$ e $W$, paralelos ao Eixo Rodoviário, e também à grande quantidade de árvores existentes ao longo do perfil, que causaram ruídos de baixa freqüência no sinal. Por estes motivos, o processamento dos dados de sísmica foi bastante difícil ocorrendo alguma ambigüidade na determinação da primeira chegada dos geofones com maiores afastamentos. Além disso, acredita-se que a 
amplitude da onda sofreu atenuação causada pelo meio, o que sugere a utilização de fontes com mais energia. $\mathrm{Na}$ Figura 3 está um exemplo de sismograma para o ponto de tiro na posição 120 metros.

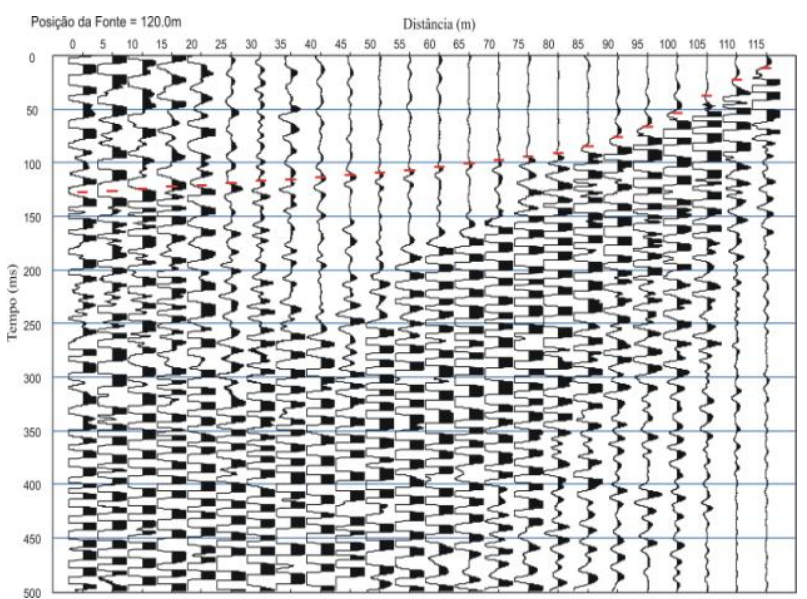

Figura 3: Exemplo de sismograma. Tiro a 120 metros do geofone de referência (posição 0).

No perfil sísmico (Figura 4) foram identificadas três camadas. A primeira apresenta uma velocidade média de $350 \mathrm{~m} / \mathrm{s}$, que deve estar relacionada ao solo (pedólito) com contribuição de aterro da época da construção de Brasília. A segunda camada possui uma velocidade média de $1360 \mathrm{~m} / \mathrm{s}$, que deve estar relacionada ao saprólito pobre em ferro (C1). A terceira camada possui uma velocidade média de $2370 \mathrm{~m} / \mathrm{s}$, e foi interpretada como um saprólito rico em ferro (C2). Ambos saprólitos são relacionados aos pacotes de ardósias roxas que ocorrem no Grupo Paranoá (Blanco, 1995).

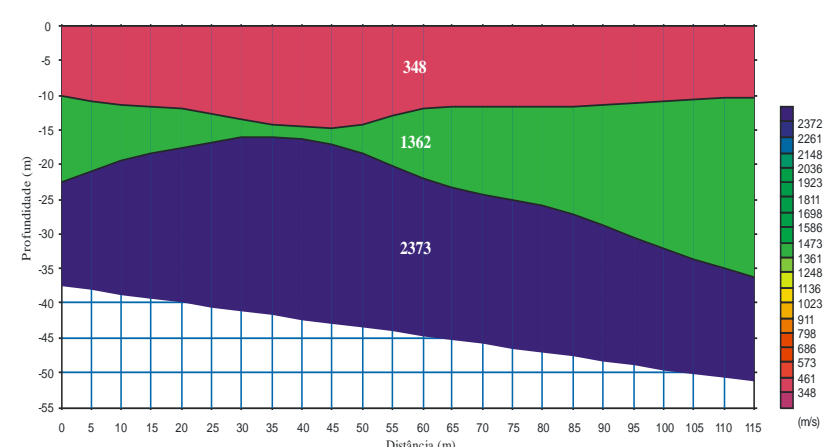

Figura 4: Modelo de velocidade obtido para a área de estudo.

Eletrorresistividade:

A eletrorresistividade gerou uma seção elétrica $2 D$ (Figura 5c), qual apresenta um solo com características heterogêneas.

A camada fina na superfície do perfil aparenta ser o solo, apresentando alta resistividade e sua profundidade varia entre dois e três metros. Esta camada não foi descriminada com o método sísmico. Logo abaixo desta camada, aparece outra com resistividade variando entre 340 a 1200 Ohm.m com profundidades de 12 metros. Este horizonte geoelétrico foi interpretado como o nível freático, e deve estar relacionado com a primeira camada observada pelo método sísmico. Nas posições de 160 a 190 metros nota-se uma zona condutiva verticalizada, que poderia ser interpretada como uma zona de falha ou de intervenção humana. A terceira camada é a mais resistiva e deve estar relacionada com as camadas de saprólito.

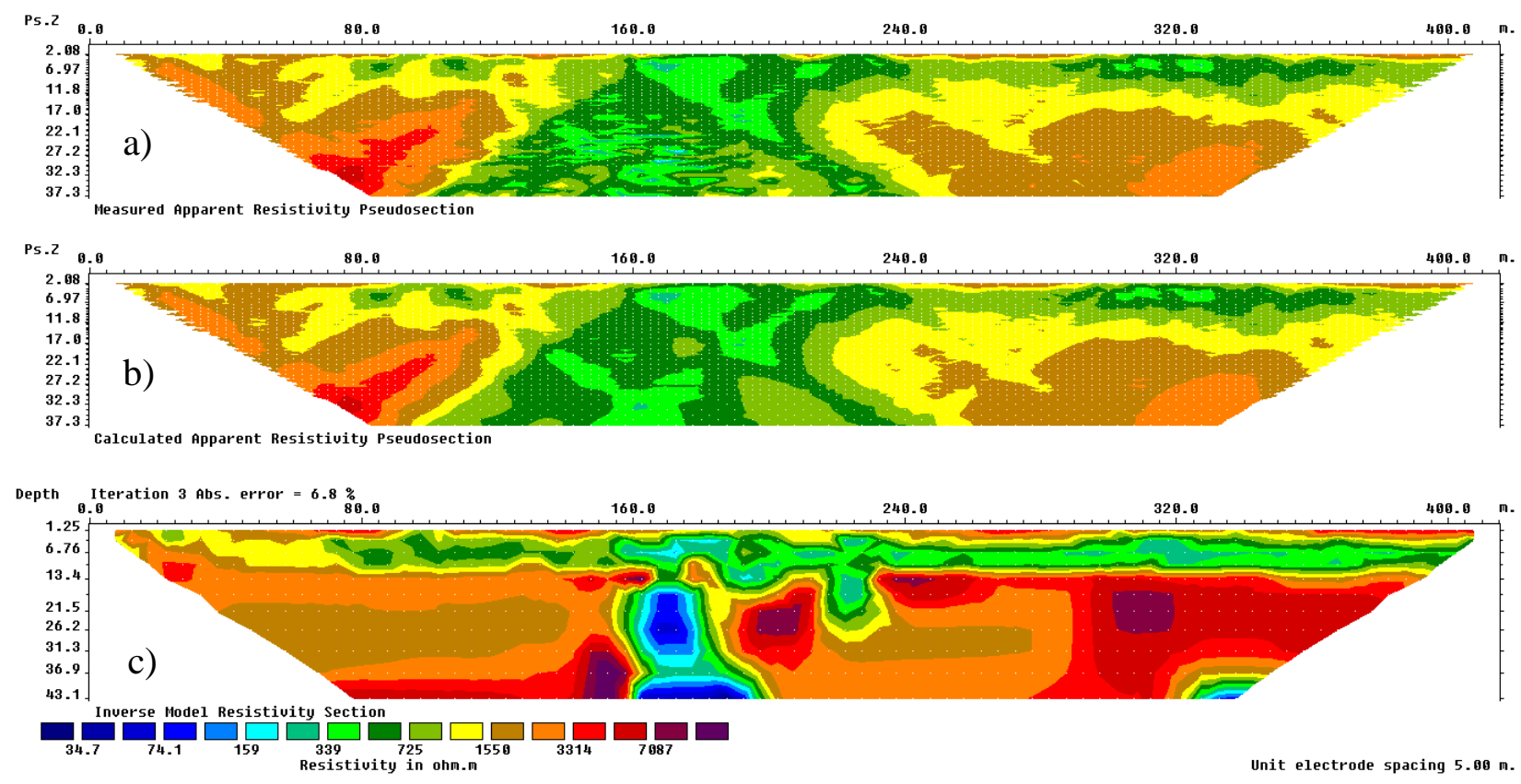

Figura 05: Perfil de eletrorresistividade para área de estudo. a) Pseudo-seção medida. b) Pseudo-seção calculada. c) Modelo de resistividade eléltrica. 


\section{Discussão e Conclusões}

Mesmo realizando os levantamentos sísmicos aos domingos, o nível de ruído ainda permaneceu alto. Isso foi causado não apenas pela passagem de veículos nos eixos $\mathrm{L}$ e $\mathrm{W}$, mas também pela presença de árvores próximas aos trechos de estudo e pela passagem de pedestres ao longo do Eixo Rodoviário para fazer exercícios físicos. Para minimizar este efeito em futuros campos pretende-se usar fontes sísmicas de maior energia e fazer levantamento com 48 geofones, melhorando assim a resolução dos dados.

Os resultados de sísmica de refração permitiram identificar a cobertura pedológica e as interfaces entre os pacotes distintos o saprólito relacionado à ardósia (C1 e $\mathrm{C} 2$ ). A primeira camada seria o solo (pedólito), a segunda estaria relacionada a um saprólito pobre em ferro (C1) e a terceira como saprólito rico em ferro (C2). As características apresentadas acima são semelhantes às mencionadas por BLANCO (1995) e MARTINS (2000).

Os resultados de eletrorresistividade mostram que é possível definir a profundidade do nível d'água nos primeiros 12 metros (o topo da zona saturada estaria em torno de 2 metros). As anomalias condutivas verticalizadas (no centro do perfil) podem estar relacionadas a uma zona de falha, ou ainda, poderia ser água percolada no solo devido à presença do posto de gasolina que faz serviços freqüentes de lava-jato. Ainda, esta anomalia poderia estar relacionada a edificações, tais como uma galeria de águas pluviais. Seriam necessários novos estudos no entorno deste perfil para confirmar estas hipóteses.

Os levantamentos preliminares, no caso da sísmica, sugerem a necessidade de uma fonte sísmica com mais energia, para melhorar a razão sinal/ruído e diminuir as ambigüidades durante a marcação das primeiras chegadas. Além disso, tanto para o método sísmico, quanto para o método da eletrorresistividade, seria interessante testar novos arranjos e parâmetros de aquisição.

\section{Agradecimentos}

Aos Professores José Eduardo Pereira Soares e José Eloi Guimarães Campos (Docentes do Instituto de Geociências/UnB) pelas valiosas discussões durante a interpretação dos resultados. À Pollyanna Araujo de Alencar pela revisão do texto. Ao doutorando Luis Anselmo da Silva e ao técnico Péricles de Brito Macedo pelo auxílio de campo. Ao Laboratório de Geofísica Aplicada (LGAUUnB) pela disponibilização dos equipamentos geofísicos e automóvel. Ao departamento de Engenharia Civil da UnB.

\section{Referências}

Alves, P. C., (2009). Cartografia Geotécnica para Obras Subterrâneas: Condições de Construções de Garagens Subterrâneas e Metrô no Plano Piloto de Brasília. Dissertação de Mestrado, Publicação G.DM 178/09,
Departamento de Engenharia Civil e Ambiental, Universidade de Brasília, Brasília, DF, 168 p.

Blanco, S. B., (1995). Aspectos de Geologia de Engenharia da Escavação do Metrô de Brasília: Trecho Asa Sul. Dissertação de Mestrado, publicação n G.DM 019/95. Departamento de Engenharia Civil e Ambiental, Universidade de Brasília, Brasília, DF,95p.

Google Earth, 2010. http://earth.google.com/.

Martins, E. S. (2000). Petrografia, Mineralogia e Geomorfologia de Rególitos Lateríticos do Distrito Federal. Tese de Doutorado, Instituto de Geociências, Universidade de Brasília, Brasília, DF, 196 p.

Metrô (2010) - Metrô - DF disponível em http://www.metro.df.gov.br/ Acessado 27de julho de 2010.

Oliveira, M. G. (1996). Mapeamento Geotécnico da Asa Sul - Brasília - DF. Dissertação de mestrado. Dissertação de Mestrado, publicação nº G.DM-036/96. Departamento de Engenharia Civil e Ambiental, Universidade de Brasília, Brasília, DF, 145 p. 